\title{
Effects of methyl isocyanate on the respiratory tract of rats
}

\author{
B NEMERY, D DINSDALE, S SPARROW, AND DE RAY \\ From the Medical Research Council, Toxicology Unit, Carshalton, Surrey SM54EF, UK
}

ABSTRACT Static exposure of rats to methyl isocyanate, for one hour, led to respiratory impairment during and after exposure. The resultant changes in breathing pattern suggest that this compound is both a sensory and a pulmonary irritant. Low concentrations resulted in extensive necrosis and loss of epithelial cells in the proximal airways but widespread alveolar damage was found only after exposure to high, lethal concentrations. At high concentrations methyl isocyanate probably caused peracute death through reflex inhibition of breathing. Animals surviving the exposure exhibited signs of airway narrowing and development of (haemorrhagic) pulmonary oedema. The epithelial lesions were repaired rapidly, but residual peribronchial fibrosis and signs of renewed injury/inflammation were apparent.

One of the striking features of the Bhopal disaster in which several thousand people were killed or injured was the lack of toxicological information on the causal agent, methyl isocyanate (MIC). ${ }^{12}$ The only relevant study available was that of Kimmerle and Eben who established that MIC was highly irritating for the skin and mucosae and concluded, from gross necropsy findings, that inhaled MIC caused pulmonary oedema. ${ }^{3}$

In an attempt to clarify the mechanisms of the acute toxicity of MIC and to identify the possible long term effects of intoxication we set out to investigate the effects of inhaled MIC on the respiratory tract of rats.

\section{Exposure conditions, materials, and methods}

One to six male LAC-P rats (weight $130-170 \mathrm{~g}$ ) were individually housed in wire cages within a 501 glass tank. A quantity of 1-500 $\mu$ l MIC (Fluka, Switzerland) was vaporised in the tank to produce nominal concentrations of $0.02,0 \cdot 1,0.25,0.5,1$, or $10 \mathrm{mg} / \mathrm{l}$. Exposure lasted one hour, except at the highest concentration used when it was 15 minutes.

Samples $(1 \mathrm{ml})$ were taken regularly from the atmosphere within the tank and analysed in a Pye series 104 gas chromatograph equipped with a flame ionisation detector. The concentrations of MIC were assessed

Received 8 July 1985 Accepted 29 July 1985 against a calibration curve obtained using solutions of MIC in dichloromethane.

Lungs were weighed before and after being dried, at $110^{\circ} \mathrm{C}$, for $24-48$ hours. Lung weights of exposed rats were expressed as a percentage of those of control rats of equivalent body weight at the time of exposure. Measurements of breathing rate $\left(f_{R}\right)$ were obtained by recording oesophageal pressure changes in rats anaesthetised with pentobarbital $(60 \mathrm{mg} / \mathrm{kg}$ intraperitoneally). Arterial $\mathrm{pH}$ and partial pressure of oxygen $\left(\mathrm{pO}_{2}\right)$ and carbon dioxide $\left(\mathrm{pCO}_{2}\right)$ were measured on an IL 413 instrument from $0.3 \mathrm{ml}$ heparinised blood drawn, anaerobically, from a cannula previously inserted in a tail artery under halothane/nitrous oxide anaesthesia.

For the morphological studies the lungs of 33 rats were expanded, through a tracheal cannula, with $2 \%$ glutaraldehyde in buffer. ${ }^{4}$ In a further 11 animals the lungs were perfused through the pulmonary artery, with the same fixative, and inflated at a pressure of $40 \mathrm{~mm} \mathrm{Hg}$ with formaldehyde saturated air. Fixative was also passed into the larynx before it was excised and immersed in fixative. The lungs were subsequently excised and cut into "transverse" slices $5 \mathrm{~mm}$ thick. Slices from the right caudal lobe were transferred to formal saline for routine histology (haematoxylin and eosin, and Van Gieson stains). Samples from the left lung were placed in fresh glutaraldehyde fixative and prepared for correlated light microscopy and transmission and scanning electron microscopy (TEM \& SEM) ${ }^{4}$ 
Results

CONCENTRAATIONS OF MIC IN THE EXPOSURE TANK

MIC concentrations, as determined by gas chromatography, were found to be below those expected from total evaporation and uniform distribution of the injected compound. A consistent decrease in concentration with time occurred even when there were no animals in the tank; it was not due to the presence of water vapour or to stratification of the gas and probably resulted from leakages. ${ }^{2}$ The concentrations given in this report are calculated initial concentrations and must be reduced by a factor of about 4 to obtain a time weighted average concentration over one hour-for example, 12.5 $\mu \mathrm{l}$ MIC injected into the 501 tank gives a nominal concentration of $0.25 \mathrm{mg} / \mathrm{l}$ or $100 \mathrm{ppm}$, but the real time weighted average concentration over one hour was between 20 and $30 \mathrm{ppm}$.

\section{CLINICAL DATA AND LETHALITY DURING EXPOSURE}

Immediately after the injection of $\mathrm{MIC}$ into the exposure tank the rats showed signs of eye and nose irritation. They stopped breathing momentarily and coughed but became only slightly agitated. Within minutes of being exposed to $0.25 \mathrm{mg} / 1$ or more they became prostrated and their breathing became slow, with gasping; a clear fluid ran from their noses. This laboured breathing was sustained throughout the exposure and led to respiratory acidosis and moderate hypoxaemia (fig 1).

Eight rats were exposed for 15 minutes to $10 \mathrm{mg} / \mathrm{l}$; four died during exposure and two shortly afterwards. The lungs of these rats were enlarged with air but with no gross oedema or haemorrhage (wet weight $110 \pm$ $5 \%$ of predicted). The wet/dry lung weight ratio (W/D ratio) was $4.93 \pm 0.05$ and similar to that of the controls (5.01 $\pm \overline{0} \cdot 10)$. Gross evidence of pulmonary oedema or haemorrhage was present only in two rats killed after exposure to $10 \mathrm{mg} / \mathrm{l}$ (wet lung weight $158 \%$ of predicted, $\mathrm{W} / \mathrm{D}$ ratio $6 \cdot 27)$.

\section{CHANGES IN BREATHING RATE DURING EXPOSURE}

When exposed to MIC, anaesthetised rats generally showed an immediate apnoea in expiration, followed by irregular breathing movements, a concentration related decrease in $f_{R}$ and complete respiratory arrest within minutes of exposure (fig 2). The decrease in $f_{R}$ was brought about mainly by a lengthening of expiration and later by apnoeic pauses between each breath. In three rats breathing through a tracheostomy cannula and exposed to $0.25 \mathrm{mg} / \mathrm{l}$ there was an initial increase in $f_{R}$ followed by a decrease due to apnoeic pauses (fig 2 ). This decrease was of lesser

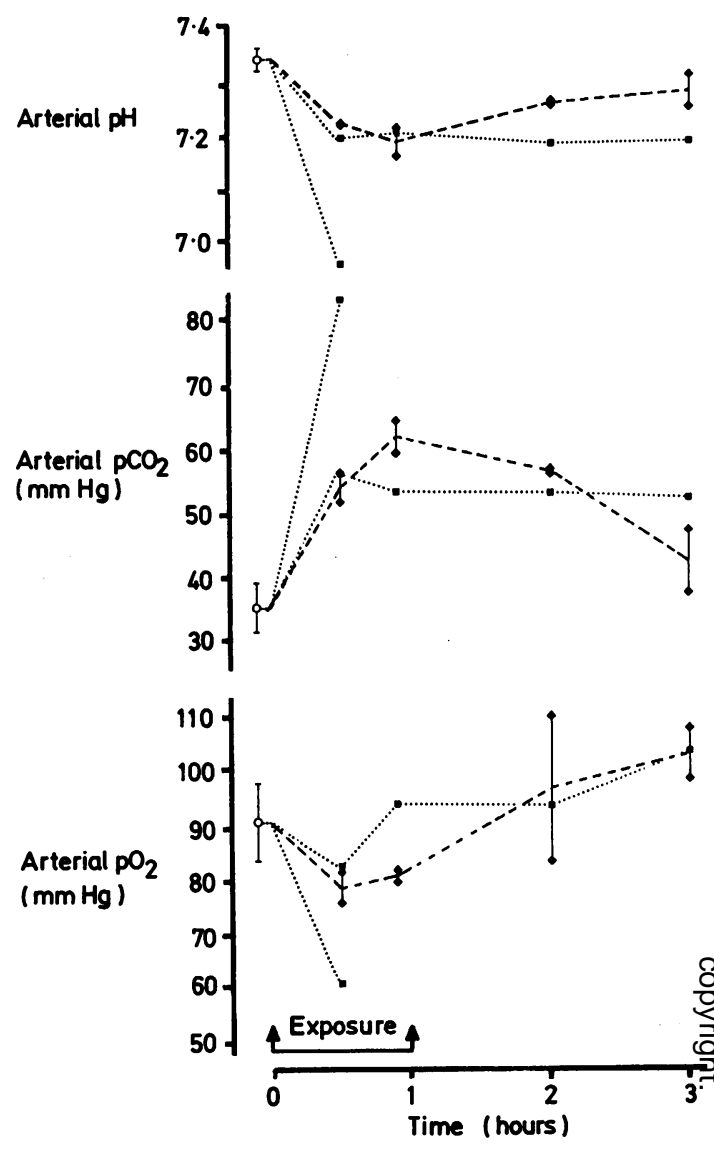

Fig 1 Effects of exposure to $\mathrm{MIC}$ on arterial $\mathrm{pH}, \mathrm{pCO}_{2}$, and $\mathrm{pO}_{2}$. Mean ( $\pm S D$ ) pre-exposure value ( $\left.\bigcirc\right)$ and individual values during and after exposure to $0.25 \mathrm{mg} / \mathrm{l}$ $(\diamond)$ or $1 \mathrm{mg} / \mathrm{l}(\square)$. One rat exposed to $1 \mathrm{mg} / \mathrm{l}$ died 45 minutes after start of exposure.

magnitude than in the normally breathing rats and no complete respiratory arrest ensued.

No evidence for laryngeal closure was obtained $\overline{0}$ when tracheal pressure changes were recorded through a $T$ cannula in a rat breathing through the $\delta$ nose and exposed to $10 \mathrm{mg} / \mathrm{l}$. In this rat recordings of heart rate and arterial blood pressure showed that the $\frac{0}{3}$ initial apnoea was accompanied by a transient rise in $D$ blood pressure and was followed by bradycardia. 을. Normal blood pressure was maintained until breath- $N$ ing had virtually stopped and the heart kept beating o until well after cessation of breathing.

\section{CLINICAL DATA AND LETHALITY AFTER}

EXPOSURE or more had a slow and laboured breathing with gasps $\stackrel{\mathcal{P}}{+}$ 

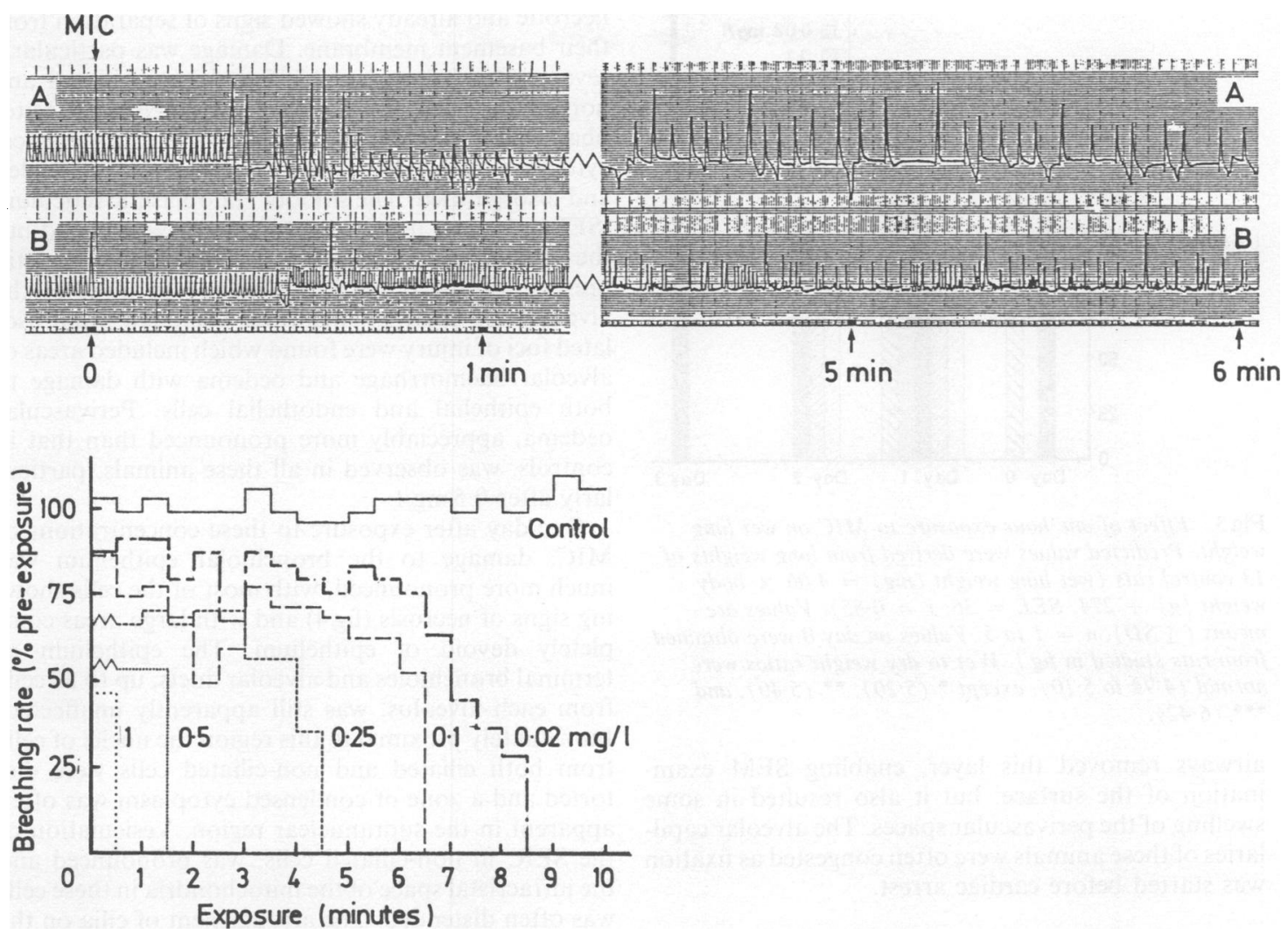

Fig 2 Effect of various concentrations of MIC on breathing rate, obtained from oesophageal pressure changes in anaesthetised rats. On the diagram each line represents values from a single animal. Pre-exposure values ranged from 50 to 72 a minute. Traces shown were obtained from two other rats exposed to $0.25 \mathrm{mg} / \mathrm{l}$, one rat breathing normally (A) and the other breathing through a tracheal cannula $(B)$.

and both inspiratory and expiratory wheeze. The data in figure 1 show that respiratory acidosis tended to improve in two rats exposed to $0.25 \mathrm{mg} / \mathrm{l}$ and to persist in the surviving rat exposed to $1 \mathrm{mg} / 1$. When killed two hours after the end of their exposure the former rats showed small increases in lung weight and in W/D ratio whereas the latter rat had more definite evidence of pulmonary oedema (fig 3 ).

During the 24 hours after exposure, rats exposed to $0.02 \mathrm{mg} / \mathrm{l}$ gained as much weight as unexposed rats, but those exposed to $0.1 \mathrm{mg} / \mathrm{l}$ or more did not eat or drink and consequently lost weight. Despite severe respiratory distress no rats exposed to $0.25 \mathrm{mg} / \mathrm{l}$ died. One rat of the nine exposed to $0.5 \mathrm{mg} / 1$ died within 24 hours. Three rats exposed to $1 \mathrm{mg} / 1$ died within 24 hours and four others were moribund and killed at this time.

The lungs of rats killed 24 hours after exposure to $0.02 \mathrm{mg} / 1$ or $0.1 \mathrm{mg} / 1$ looked normal and had normal weights and W/D ratio (fig 3 ). The rats exposed to higher doses had air filled lungs, often with one or more whole lobes consolidated and haemorrhagic. Increases in wet and dry lung weight were small after $0.25 \mathrm{mg} / 1$, moderate after $0.5 \mathrm{mg} / 1$, and larger after $1 \mathrm{mg} / \mathrm{l}$ (fig 3).

The signs of respiratory distress disappeared within two days, the animals started to gain weight from the third day after exposure, and lung weights returned to normal. No late deaths occurred during four months of observation after exposure to $0.25 \mathrm{mg} / \mathrm{l}$.

\section{LIGHT AND ELECTRON MICROSCOPY Control rats}

The bronchiolar epithelium of all control animals was normal and intact. In lungs fixed with vapour and vascular perfusion this epithelium was covered by a layer of mucus that enveloped the surface features of the cells. The instillation of liquid fixative into the 


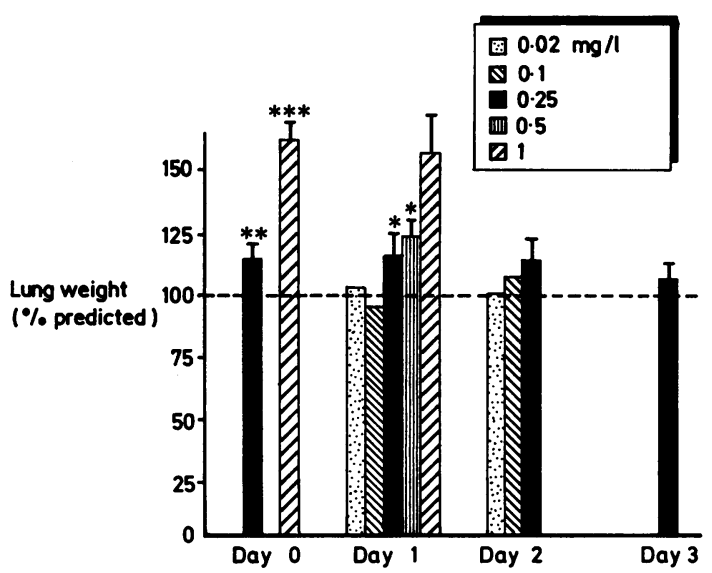

Fig 3 Effect of one hour exposure to MIC on wet lung weight. Predicted values were derived from lung weights of 13 control rats (wet lung weight $(\mathrm{mg})=4.06 \times$ body weight $(g)+274$. SEE $=36 ; r=0.85)$. Values are means ( $\pm S D$ ), $n=1$ to 5 . Values on day 0 were obtained from rats studied in fig 1 . Wet to dry weight ratios were normal $(4.93$ to $5 \cdot 10)$, except $*(5 \cdot 20),{ }^{* *}(5 \cdot 40)$, and *** $(6 \cdot 42)$.

airways removed this layer, enabling SEM examination of the surface, but it also resulted in some swelling of the perivascular spaces. The alveolar capillaries of these animals were often congested as fixation was started before cardiac arrest.

Rats exposed to low concentrations of MIC

A few, small autophagic vacuoles were found in ciliated cells from the larger bronchioles of animals 24 hours after exposure to $0.02 \mathrm{mg} / 1 \mathrm{MIC}$. In all other respects the histological and ultrastructural appearance of lungs from rats exposed to this concentration of MIC was similar to that of control samples.

Rats exposed to lethal concentrations of MIC Exposure to a lethal concentration of MIC $(1 \mathrm{mg} / \mathrm{l})$ resulted in the destruction of all the epithelial cells of the larynx and airways within two hours and most of these cells were stripped from the basement membrane within 24 hours. Epithelial damage was not restricted to the airways but extended into many of the alveoli. Cellular injury was particularly common in type I pneumocytes but also occurred in type II cells and endothelial cells lining alveolar capillaries. This damage was accompanied by massive alveolar oedema and haemorrhage.

Rats exposed to intermediate concentrations of MIC Within two hours of exposure to $0 \cdot 1,0 \cdot 25$, and $0.5 \mathrm{mg} / \mathrm{l}$ there was severe damage to the epithelium of the larger airways. Many of the epithelial cells were
Nemery, Dinsdale, Sparrow, and Ray

necrotic and already showed signs of separation from $\overline{\bar{\alpha}}$ their basement membrane. Damage was particularly $z$ severe after $0.5 \mathrm{mg} / \mathrm{l}$ and affected both ciliated and $\stackrel{\odot}{\circ}$ non-ciliated cells of the larger bronchioles. Autophagy was common in both cell types and the apical $\stackrel{?}{\stackrel{9}{9}}$ cytoplasm of many ciliated cells was both distended and disorganised. The smooth endoplasmic reticulum 음 (SER) of many non-ciliated cells was vesiculated but $\frac{\rho}{\vec{\rho}}$ the characteristic granules of these cells were still $\stackrel{\curvearrowright}{\varrho}$ present. The terminal bronchioles and most of the alveoli were apparently normal, although small, iso- $\overrightarrow{0}$ lated foci of injury were found which included areas of. alveolar haemorrhage and oedema with damage to $\vec{\omega}$ both epithelial and endothelial cells. Perivascular $\stackrel{\sim}{\nabla}$ oedema, appreciably more pronounced than that in controls, was observed in all these animals, particu- 3 larly after $0.5 \mathrm{mg} / \mathrm{l}$.

One day after exposure to these concentrations of $\frac{\sim}{N}$ MIC, damage to the bronchiolar epithelium was much more pronounced, with most of the cells show- 8 ing signs of necrosis (fig 4) and with large areas completely devoid of epithelium. The epithelium of terminal bronchioles and alveolar ducts, up to 30 cells $\square$ from each alveolus, was still apparently unaffected. Immediately proximal to this region the nuclei of cells $\frac{\mathbb{}}{3}$ from both ciliated and non-ciliated cells were distorted and a zone of condensed cytoplasm was often $\stackrel{\mathbb{1}}{-}$ apparent in the supranuclear region. Vesiculation of $\vec{\oplus}$ the SER, in non-ciliated cells, was pronounced and or the intracristal space of the mitochondria in these cels was often distended. The arrangement of cilia on the surface of most of the ciliated cells was disorganised and many of these cells exhibited ciliated intracellular vacuoles or intracytoplasmic cilia, or both. Foci of $\frac{\circ}{D}$ injury within the lung parenchyma were larger than $\stackrel{\varrho}{\rightarrow}$ those found two hours after exposure and involved $\overline{0}$ numerous alveoli. Inflammatory cells, particularly macrophages and immature neutrophils, together with erythrocytes and fibrin were usually associated with these foci.

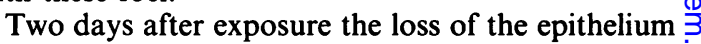
from larger airways was almost complete but signs of cell proliferation and repair were already evident. The lining of terminal bronchioles remained undamaged. $\delta$ Foci of alveolar damage were no larger than those found on the previous day, although inflammatory $\frac{\text { 의 }}{2}$ cells were much more numerous. These cells were also found surrounding many of the bronchioles. Repair of the bronchiolar epithelium was observed four and seven days after exposure to $0.25 \mathrm{mg} / 1$.

A low epithelium, mainly composed of non-ciliated $N$ cells, lined most of the larger bronchioles within one week of exposure. Peribronchial oedema, which 0 appeared to constrict some bronchioles, was still evi-o dent at this time. Peribronchial, and some interstitial, $\underset{\varnothing}{\varnothing}$ fibrosis was present, and there were possible signs of $\stackrel{\mathcal{Q}}{?}$ 


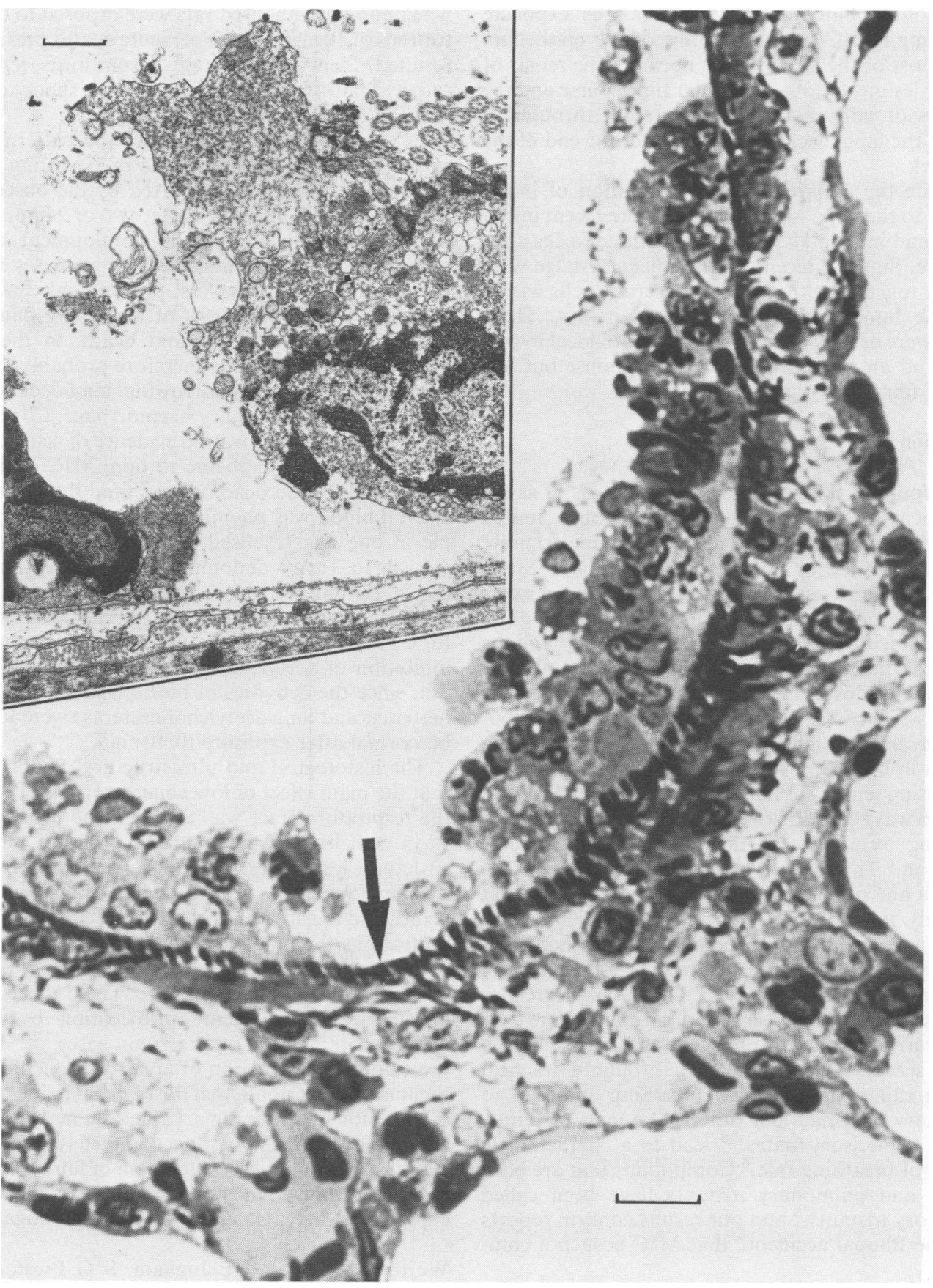

Fig 4 Bronchiolar epithelium of a rat killed 24 hours after one hour exposure to $0.25 \mathrm{mg} / \mathrm{l} \mathrm{MIC}$, showing exposure of basement membrane (arrow) and extensive cell injury. Resin section stained with toluidine blue (internal marker represents $10 \mu \mathrm{m}$ ). Inset shows ultrastructural features of an injured ciliated cell adjacent to an exposed region of the basement membrane (internal marker represents $1 \mu \mathrm{m}$ ). 
bronchiolitis obliterans. Three weeks after exposure to $0.25 \mathrm{mg} / 1 \mathrm{MIC}$ the appearance of the epithelium lining most of the airways was normal. The repair of alveolar lesions followed a similar time course and the numbers of inflammatory cells, present throughout most of the lung, declined rapidly after the end of the first week.

Despite the apparently rapid resolution of initial damage to the lung, isolated foci of more recent injury were found in animals killed two or three weeks after exposure. Signs of recent alveolar haemorrhage were present, together with groups of necrotic cells within both the lumen and epithelium of airways. These lesions were usually accompanied by both local hyperplasia and an active inflammatory response but few signs of fibrosis.

\section{Discussion}

The purpose of this toxicological study was to assess the principal biological effects of MIC on a limited number of animals rather than to determine accurate no effect levels or lethal concentrations. Static exposure conditions were chosen for reasons of expedience and safety. Overall our results are in good agreement with those of Kimmerle and Eben, ${ }^{3}$ and the biological indexes examined showed a good correlation with dose.

A classic bioassay for assessing the irritating properties of airborne chemicals is based on measuring changes in breathing rate, usually in mice. ${ }^{56}$ Chemicals causing sensory irritation of the nasal mucosa and upper airways cause a reflex apnoea and a decrease in breathing rate by lengthening the duration of expiration. ${ }^{6}$ This reflex, which is accompanied by bradycardia and peripheral vasoconstriction, operates at extremely low concentrations. In experimental animals it is concentration dependent, and is not abolished by anaesthesia, but it may be prevented by bypassing the upper airways. ${ }^{5}$ This reflex correlates well with the effects experienced by man. ${ }^{6}$ Pure pulmonary irritants such as phosgene and nitrogen dioxide, or sensory irritants inhaled through a tracheal cannula cause rapid shallow breathing and lead to pulmonary oedema, ${ }^{5}$ but other pulmonary irritants, notably some isocyanates, ${ }^{78}$ lead to a characteristic slowing of breathing rate. ${ }^{6}$ Compounds that are both sensory and pulmonary irritants have been called respiratory irritants, ${ }^{5}$ and our results confirm reports from the Bhopal accident ${ }^{9}$ that MIC is such a compound.

The data on breathing rate shown in fig 2 were obtained from anaesthetised rats, in which the bradypnoea reflex was accentuated to the extent that complete respiratory arrest rapidly occurred. Such deaths, within minutes of exposure, were also found when non-anaesthetised rats were exposed to concen- $\overline{\overline{0}}$ trations of $10 \mathrm{mg} / \mathrm{l}$. These peracute deaths presumably $\frac{2}{z}$ resulted from a "syncope respiratoire réflexe"10 rather than from cardiocirculatory shock or pulmonary oedema.

In rats surviving the exposure the pattern of the severe dyspnoea was indicative of persisting airway $\overline{0}$ obstruction. This was supported by the observation $\bar{c}$ that the lungs of rats killed after two or 24 hours were $\overparen{D}$ filled with trapped air. The development of pulmonary oedema was indicated by increases in lung $\infty$ weight, but this was less pronounced than that $\overrightarrow{0}$ resulting from some forms of toxic lung damage. ${ }^{11} \overrightarrow{\vec{A}}$ Respiratory insufficiency, and death, in the hours $\vec{\omega}$ after exposure to MIC is therefore probably due to a $\mathrm{O}$ combination of airway narrowing, lung oedema, and, $\frac{\mathbb{D}}{3}$ in some cases, pulmonary haemorrhage. Contrary to speculations, ${ }^{12}$ there was no evidence of acute cyanide ? intoxication after exposure to pure MIC. Indeed, in $\vec{N}$ the animals found dead or moribund the venous and arterial blood was obviously desaturated-for example in one anaesthetised rat exposed 24 hours pre- $\frac{}{3}$ viously to $1 \mathrm{mg} / \mathrm{l}$ abdominal aorta $\mathrm{pO}_{2} 41 \mathrm{~mm} \mathrm{Hg}$, $\mathrm{pCO}_{2} 121 \mathrm{~mm} \mathrm{Hg}$. Also, plasma and 24 hour urine

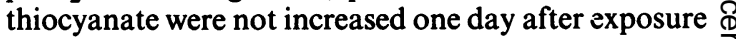
to $0.5 \mathrm{mg} / \mathrm{l}$. Cholinergic poisoning consequent to $\bar{\square}$ inhibition of acetylcholinesterase may also be ruled $\subseteq$ out, since the activities of both plasma butyrylcholi- $\overrightarrow{0}$ nesterase and lung acetylcholinesterase were found to $\infty$ be normal after exposure to $10 \mathrm{mg} / \mathrm{l}$.

The histological and ultrastructural findings sho that the main effect of low concentrations of MIC of the respiratory tract was to injure the proximal air- o ways with little alveolar injury. Many of the ultrastructural lesions resemble those caused by $\mathrm{NO}_{2}$ but $\stackrel{\mathbb{Q}}{\circ}$ this gas injures the central region of the pulmonary $\overrightarrow{\overrightarrow{0}}$ acinus and the adjacent bronchioles. ${ }^{1314}$ At high con- $\exists$ centrations the lung parenchyma was also damaged, with resulting interstitial and alveolar oedema, inflammation, and haemorrhage. These effects resem- $\bar{O}$ ble the results of acute intoxication by toluene $\frac{\Phi}{3}$ diisocyanate ${ }^{1516}$ and other irritant gases. ${ }^{1718}$ Despite the complete destruction of areas of bronchiolar epithelium, even at non-lethal doses, the repair capability $\delta$ of the epithelium was remarkable, and in the surviving animals an epithelium soon completely covered the 을 airways. The possible development of fibrosis or localised lung injury, or both, long after the end of $\frac{D}{O}$ exposure to MIC is currently under investigation.

We thank B Biles, J E Ingham, S G Preston, C A N Thompson, and B J Wright for their help in preparing N tissues for light and electron microscopy, $\mathrm{T}$ Lister for the blood gas analyses, D J Read for measuring cholinesterase levels, C J Vesey (anaesthetics laboratory, St Bartholomew's Hospital) for measuring thio- 
cyanate levels, J T Foard for the illustrations, and J A Bryant and $G$ Zdaniecki for typing the manuscript.

We are also grateful to Dr L Magos for his supervision of the early exposure experiments, Dr E Bailey for advice on chromatography, and Drs W N Aldridge, M K Johnson, and A J Newman Taylor (Brompton Hospital) for stimulating discussions.

\section{References}

${ }^{1}$ Anonymous. Calamity at Bhopal. Lancet 1984;ii:1378-9.

${ }^{2}$ Dagani R. Data on MIC's toxicity are scant, leave much to be learned. Chemical and Engineering News 1985:63:37-40.

${ }^{3}$ Kimmerle R, Eben A. Zur Toxicität von Methylisocyanat und dessen quantitativer Bestimmung in der Luft. Arch Toxikol 1964;20:235-41.

${ }^{4}$ Dinsdale D, Verschoyle RD, Ingham JE. Ultrastructural changes in rat Clara cells induced by a single dose of OSStrimethylphosphorodithioate. Arch Toxicol 1984;56:59-65.

${ }^{5}$ Alarie Y. Sensory irritation by airborne chemicals. CRC Crit Rev Toxicol 1973;2:299-363.

${ }^{6}$ Alarie Y. Toxicological evaluation of airborne chemical irritants and allergens using respiratory reflex reactions. In: Leong BKJ, ed. Inhalation toxicology and technology. Ann Arbor: Ann Arbor Science, 1981:207-31.

${ }^{7}$ Weyel DA, Rodney BS, Alarie Y. Sensory irritation, pulmonary irritation, and acute lethality of a polymeric isocyanate and sensory irritation of 2,6-toluene diisocyanate. Toxicol Appl Pharmacol 1982;64:423-30.

${ }^{8}$ Weyel DA, Schaffer RB. Pulmonary and sensory irritation of diphenylmethane-4,4'- and dicyclohexylmethane-4,4'- diisocyanate. Toxicol Appl Pharmacol 1985;77:427-33.

${ }^{9}$ Andersson N, Kerr Muir M, Mehra V. Bhopal eye. Lancet 1984;ii:1481.

${ }^{10}$ Magne N, Mayer A, Plantefol L. La mort par inhibition et l'irritation des premières voies respiratoires. Annales de Physiologie 1925;1:428-43.

${ }^{11}$ Verschoyle RD, Cabral JRP. Investigation of some trimethyl and triethyl phosphorothioates with particular reference to those causing lung damage. Arch Toxicol 1982;51:221-31.

${ }^{12}$ Hamlyn M. Bhopal: was cyanide the culprit? The Times 1985 Jan 17.

${ }^{13}$ Evans MJ. Oxidant gases. Environ Health Perspect 1984;55:85-95.

${ }^{14}$ Stephens RJ, Freeman G, Crane SC, Furiosi NG. Ultrastructural changes in the terminal bronchiole of the rat during continuous, low-level exposure to nitrogen dioxide. Exp Mol Pathol 1971;14:1-19.

${ }^{15}$ Duncan B, Scheel LD, Fairchild EJ, Killens R, Graham S. Toluene diisocyanate inhalation toxicity: pathology and mortality. $\mathrm{Am}$ Ind Hyg Assoc $J$ 1962;23:447-56.

${ }^{16}$ Klavis G, Schulz LC. Tierexperimentelle Untersuchungen über spezifische Wirkungen und Spätfolgen nach Desmodur 15. Arch Toxicol 1959;17:338-46.

${ }^{17}$ Charan NB, Myers CG, Lakshminarayan S, Spencer TM. Pulmonary injuries associated with acute sulfur dioxide inhalation. Am Rev Respir Dis 1979;119:555-60.

${ }^{18}$ Kaufman J, Burkons D. Clinical, roentgenologic, and physiologic effects of acute chlorine exposure. Arch Environ Health 1971;23:29-34.

\section{Destruction of manuscripts}

From 1 July 1985 articles submitted for publication will not be returned. Authors whose papers are rejected will be advised of the decision and the manuscripts will be kept under security for three months to deal with any inquiries and then destroyed. 